\title{
Article
}

\section{Expertise in soccer teams: A thematic inquiry into the role of shared mental models within team chemistry}

Gershgoren, Lael, Basevitch, Itay, Filho, Edson, Gershgoren, Aaron, Brill, Yaron S., Schinke, Robert J. and Tenenbaum, Gershon

Available at http://clok.uclan.ac.uk/14172/

Gershgoren, Lael, Basevitch, Itay, Filho, Edson ORCID: 0000-0002-8548-4651, Gershgoren, Aaron, Brill, Yaron S., Schinke, Robert J. and Tenenbaum, Gershon (2015) Expertise in soccer teams: A thematic inquiry into the role of shared mental models within team chemistry. Psychology of Sport and Exercise, 24 . pp. 128-139. ISSN 1469-0292

It is advisable to refer to the publisher's version if you intend to cite from the work. http://dx.doi.org/10.1016/j.psychsport.2015.12.002

For more information about UCLan's research in this area go to http://www.uclan.ac.uk/researchgroups/ and search for <name of research Group>.

For information about Research generally at UCLan please go to http://www.uclan.ac.uk/research/

All outputs in CLoK are protected by Intellectual Property Rights law, including Copyright law. Copyright, IPR and Moral Rights for the works on this site are retained by the individual authors and/or other copyright owners. Terms and conditions for use of this material are defined in the policies page. 
Expertise in Soccer Teams: A Thematic Inquiry into the Role of Shared Mental Models within Team Chemistry

Lael Gershgoren ${ }^{\mathrm{a}}$, Itay Basevitch ${ }^{\mathrm{b}}$, Edson Filho ${ }^{\mathrm{c}}$, Aaron Gershgoren ${ }^{\mathrm{d}}$, Yaron S. Brille, Robert J. Schinke $^{\mathrm{f}}$, Gershon Tenenbaum ${ }^{\mathrm{g}}$

${ }^{a}$ Zinman College for Physical Education \& Sport Sciences, Wingate Institute, Israel

${ }^{\mathrm{b}}$ Anglia Ruskin University, United Kingdom

${ }^{c}$ University of Central Lancashire, United Kingdom

${ }^{\mathrm{d}}$ Israel Institute of Technology (Technion), Israel

${ }^{\mathrm{e}}$ Florida State University, United States

${ }^{\mathrm{f}}$ Laurentian University, Canada 


\begin{abstract}
Aims: The purpose of the current study was to establish a conceptual framework of team chemistry components in sport with an emphasis on Shared Mental Models (SMM).

Method: Elite soccer coaches $(n=6)$ and players $(n=3)$ were interviewed using a semistructured interview guide. An inductive thematic analysis was employed to analyze the data.

Results: Four themes related to team chemistry components were identified: (1) members' characteristics (i.e., demographic data, on-field characteristics, and member's ego), (2) coachplayers interactions (i.e., professional interaction and emotional intelligence of coaches), (3) interactions among the players (i.e., professional understanding, efficacy beliefs, team cohesion, players' emotional intelligence, team roles, and goals), and (4) interactions with environmental factors (i.e., owners, management, fans, and media).
\end{abstract}

Conclusions: The cognitive components of the team chemistry model were clustered to establish a conceptual framework of SMM. Furthermore, the cognitive-affective-social-behavioral linkage of team chemistry and athletic performance is examined in light of the emerged model and conceptual framework. Implications and future directions are also discussed.

\title{
Expertise in Soccer Teams: A Thematic Inquiry into the Role of Shared Mental Models
}

\section{within Team Chemistry}

Individuals frequently collaborate to enhance their team's performance (Colin, 2003). Such collaborations have been acknowledged as especially important in situations in which a broader knowledge foundation and different skills are necessary for efficient decision-making (Kellermanns, Floyd, Pearson, \& Spencer, 2008). In their conceptual framework on expert teams, Eccles and Tenenbaum (2004) emphasized social (e.g., communication) and cognitive (e.g., shared cognitions) components to be crucial for reaching coordination in the pursuit of superior 
collective performance. Specifically, the concepts of teamwork and taskwork knowledge have been proposed to underlie team coordination (Cannon-Bowers \& Salas, 1998; Klimoski \& Mohammed, 1994; Mclntyre \& Salas, 1995). Teamwork knowledge refers to implicit knowledge of actions made by other teammates. Taskwork knowledge centers on the team member's knowledge pertaining to the performance requirements of a specific role in the team (Mohammed, Ferzandi, \& Hamilton, 2010). Eccles and Tenenbaum (2004) have exemplified the application of taskwork and teamwork knowledge in sports such as football, and the differences between them. Accordingly, taskwork was represented by the quarterback's ability to execute a pass that reaches its targeted destination in space and time. Yet, to complete the task successfully, the quarterback depends on teamwork (e.g., teammates blocking the defensive line from reaching him, the running back faking receiving the ball, and other potential receivers distracting the opponents from identifying the real target). As players transfer teams, their taskwork knowledge mostly holds. Nevertheless, new teamwork elements of the task must be acquired (Eccles \& Tenenbaum).

Particular interest has been devoted to Shared Mental Models (SMM) within teams. Presented as "an organized understanding or mental representation of knowledge that is shared by team members" (Mohammed, Klimoski, \& Rentsch, 2000, p. 123), SMM has been recently investigated in various domains, including the military (e.g., Mathieu, Heffner, Goodwin, Salas, \& Cannon-Bowers, 2000), education (e.g., Johnson, Khalil, \& Spector, 2008), and medicine (Lu \& Lajoie, 2008). For example, using a military simulation task, shared taskwork and teamwork mental models were found to load significantly on team processes (i.e., strategies, cooperation, and communication). In return, team processes loaded significantly on team effectiveness (Mathieu et al., 2000). Similar results pertaining to shared teamwork cognition were found by 
Zhou and Wang (2010) who aimed at capturing the moderating effect of SMM on the relationship between team process and performance. To meet this end, 50 three-person teams in a simulated construction project planning program were examined. Specifically, every member of the team was assigned to be either a project manager, procurement manager, or human resources manager. The roles and task were designed to acquire collaboration alongside role specialization. For example, work load had to be synchronized with the project property although the work load was set by the human resources manager and project property by the project manager. Successful performance was defined as creating an optimized construction plan and operating it within time limit and minimum expenses. Results revealed that teamwork mental models moderated the relationship between team processes (both transition and action processes) and performance. In other words, enhanced performance was increasingly associated with team processes in teams that shared more similar teamwork mental models.

The value and importance of SMM has been also recognized in the sporting domain. As posited by Eccles and Tenenbaum (2004), a team of experts is not necessarily an expert team. Yet, thus far, only scarce attempts have been made to conceptually explain and investigate team cognition in sport (Gershgoren, Filho, Tenenbaum, \& Schinke, 2013). Conceptual frameworks have been published by Eccles (2010), Eccles and Johnson (2009), Eccles and Tenenbaum (2004, 2007), and in a special issue of the International Journal of Sport and Exercise Psychology (IJSEP, 2006). SMM investigations in sport have centered on SMM similarity (i.e., consensus) and accuracy (i.e., quality) in basketball teams (Webber, Chen, Payne, Marsh, \& Zaccaro, 2000), and rugby officials (Mascarenhas, Collins, \& Mortimer, 2005).

Derived from these conceptual frameworks and investigations, and Eccles and Tenenbaum's (2004) framework of SMM and team coordination, a qualitative inquiry was 
conducted to examine coaches' ideation of SMM (Gershgoren et al., 2013). Gershgoren et al., observed and interviewed two collegiate soccer coaches (i.e., head coach and assistant coach) for the duration of a season. A content analysis was then inductively and deductively employed. Game intelligence and game philosophy were identified as the two components that underlie SMM. Game intelligence centered on SMM association with anticipation, creativity, knowing each other's abilities, and experience in the sport. For example, anticipation (i.e., knowing what is about to happen and which actions will be followed by teammates and opponents) was claimed important as it allows players to make decisions early and minimize their dependence on reaction time (Eccles \& Tenenbaum, 2004; Reimer, Park, and Hinsz, 2006; Tenenbaum \& Bar-Eli, 1993). Game philosophy included the association between SMM and (a) tactical understanding, (b) agreement between the coaches and the players, and (c) agreement among players. On that matter, the coaches postulated that despite them determining the game plan, the players are the ones who eventually implement it. Therefore, the extent of agreement between the players and the coaches, and among the players, is essential for producing coordinated efforts.

The aforementioned components can be hierarchically presented. Thus, game philosophy (i.e., strategy and tactics) centers on the sharedness of relatively broad and abstract mental models while game intelligence (e.g., experience, knowing each other's abilities, creativity, and anticipation) relatively addresses the shardness of more specific and "on field" mental models. Indeed, the coaches claimed that tactical components such as formation (i.e., the players' initial positions; e.g., 4-4-2, 4-5-1) provide a "bigger picture" to the players, establishing a shared basic schema for performance execution. Then, a more accurate and situational-related schema can be developed integrating the bigger picture with other dynamic information (e.g., players' abilities, the situation on the field, the score, etc). 
Gershgoren et al.'s (2013) inquiry also afforded the emergence of a holistic conceptual framework of team chemistry, comprising of emotional and social dimensions, in addition to the cognitive (SMM) one. Specifically, efficacy beliefs and emotional support comprised the affective dimension while fair approach and social/challenge support comprised the social dimension. Thus, team chemistry represents the interacting components that "spin the web of a team", and determines its ability to perform. The interaction among shared cognitions, sociobehaviors, and affections in sports has been conceptually noted as crucial in competitive athletic settings (Tenenbaum et al., 2009). Nevertheless, it remains to develop a sound research design to examining this phenomenon (Eccles \& Tenenbaum, 2004).

\section{Purpose}

Although Gershgoren et al.'s (2013) pioneer study afforded the emergence of interesting and important data, it suffered several limitations, including the number of coaches being investigated. Although saturation was reached with only two coaches, supplementary data may have emerged with additional coaches. Moreover, coaches of professional teams may approach the topics of team chemistry and SMM components from a different perspective than collegiate coaches and may offer unique insights on these constructs. The present study is, therefore, an attempt to further understand the processes and components of SMM within team chemistry in professional sport teams.

Accordingly, the first purpose of this study was to identify elite coaches' and players' perception pertaining to team chemistry. The second purpose of this qualitative inquiry was to identify what elite coaches/players perceive SMM to be and how it operates within team chemistry to achieve team effectiveness. In the current study, a qualitative approach, allowing for 
further exploration of various relevant variables simultaneously as well as their interrelations, was employed to address these multi-dimensional phenomena. .

\section{Method}

This study is an attempt to more thoroughly understand expert coaches' and players' perception of team chemistry and SMM within it. Inductive thematic analysis was deemed the most appropriate qualitative approach for the current study. Thematic analysis is commonly used in studies where the purpose is to capture people's experiences and views or construct/represent a specific phenomenon in a specific context (Braun \& Clarke, 2013).

\section{Participants}

Selection of participants was based on purposive sampling procedures oriented to obtain "information rich cases." Given that there is no rule of thumb for sample size in qualitative research, the number of participants was not determined in advance (see Creswell, 2008). Instead, experts were recruited until saturation was reached (e.g., the contribution of each additional interview became negligible; see Patton, 2002). Six elite coaches and three elite players (i.e., to be termed Experts onward) from seven different teams in the Israeli premier league agreed to participate in the study. Coaches and players complemented each other's views and provided together a comprehensive insight to the topic under investigation.

At the time of data collection, the Israeli national team was ranked as number 25 in the FIFA World Ranking. The coaches' age was $M=43.33(S D=9.04)$. Five of the coaches held a "soccer pro" coaching certificate (i.e., the highest soccer coaching certificate available in the world), and were currently coaching an Israeli premier league soccer team. The sixth coach retired, held an advanced coaching certificate (i.e., the second highest soccer coaching certificate available), and appeared in more than 350 games as a player in the Israeli premier league. 
Overall, all the coaches are considered successful having nearly 12 years of experience $(M=$ 11.67) in coaching, and over half of those years $(M=6.83)$ were spent in the Israeli primer league. In addition, the coaches had $M=13.5$ years of experience as soccer players with $M=$ 9.33 as players in the Israeli premier league. Two of the coaches were former national team players with $M=25.5$ international appearances. The elite players could be considered veteran players with $M=16.67$ years of experience in the Israeli Premier league. All of the players were former national team players with $M=72.33$ international performances.

\section{Data Collection}

Telephone calls were followed up by personal contact in order to establish rapport between the researchers and the experts. The coaches and players signed a consent form, approved by an Institutional Review Board, prior to data collection. A semi-structured interview was used as it allows for flexibility and convenience yet is considered an appropriate method to retrieve information (Patton, 2002). This method also allows the researchers to complement the core set of questions with additional questions that correspond to the unique flow of each interview. The open-ended questions (e.g., what is team "chemistry" in your opinion? What does the term SMM mean to you? What does SMM comprise of in your opinion?) were developed based on (a) Gershgoren et al.'s (2013) model of team chemistry, (b) Eccles and Tenenbaum's (2004) team coordination conceptual framework, and (c) brain storming sessions involving five sport psychology consultants. Probing techniques (i.e., detail probes, elaboration probes, clarification probes, and contrasting probes) were employed to ensure data richness and quality. The interviews lasted 25 to 90 minutes. At the beginning of the interview the research topic was presented through a short introduction. Most of the interviews occurred at the experts' places of residence. However, a few interviews were conducted either at a public place (e.g., a restaurant) 
or at the club facility. The interviews were video recorded and subsequently (a) transformed to computer files, (b) kept under a password, and (c) deleted from the video camera.

\section{Data Analysis}

Thematic analysis is a qualitative analytic method widely used in psychology (Braun \& Clarke, 2006). The current project draws, in part, on the more specific form of interpretive thematic analysis, whereby the analysis is driven by the data in an inductive process. The first two authors followed a six-stage procedure, similar to that proposed by Braun and Clarke, to analyze the current data. In the familiarization stage, the interviews, which were all conducted by the first author, were transcribed verbatim from the video recording. The written transcripts were read several times before advancing to the next stage. Second, the transcripts were thoroughly examined and the creation of provisional labels was developed in relation to each transcript through notes in the margins. The third stage centered on the generation of themes and subthemes. This process was iterative as the authors cycled between specific terms and overarching terms, which delineated into themes and sub-themes. Fourth, quotations were selected as the richest and clearest representations of each sub-theme. Fifth, a provisional thematic map was generated, extending Braun and Clarke's guidelines in order to provide a visual representation in a skeletal structure. In the sixth stage, the analysis was finalized into its current formal structure. In the seventh / final stage, the authors undertook the writing of the manuscript, engaging with the results and contextualizing these within the current manuscript.

\section{Trustworthiness}

Several steps were taken to augment the trustworthiness of this project that aligned with guidelines proposed by Lincoln and Guba (1985) and also Maxwell (2001). These guidelines confirmed with the post-positivist epistemological assumptions adopted within the current 
project. In this current study, data triangulation was sought through multiple sources, including athletes and coaches. This investigation included nine soccer experts as they were successively recruited until the contribution of each additional interview became negligible (i.e., obtaining saturation). Hence, saturation was sought, and in keeping with existing suggestion that saturation can be achieved through 15 participants +/- 10 (see Patton, 2002), the authors met this threshold with nine participants. Second, elite soccer coaches and athletes participated, providing valuable information pertaining to the matter under investigation from various vantages. For example, where the athletes were able to comment about SMM and team chemistry from the vantage of being an athlete in the thick of a performance, the coaches were able to reveal how SMM and team chemistry were engineered and how these parlayed into successful performance. A member check was also utilized twice during the analysis. Initially, all the verbatim interviews were summarized and sent back to the experts for confirmation. Within this initial step, the authors encouraged the participants to modify their responses by deleting or adding to the initial interviews and tweaking language as the participants deemed necessary. In addition, after the conceptual model was developed, it was approved by one of the expert coaches as a comprehensive model that integrates all the necessary elements. Triangulation of investigators procedure was conducted to seek consensus during the data analysis. Two researchers analyzed the data separately. These two researchers have undertaken several qualitative projects relating to SMMs. As most of the components were included in both models, disagreements were discussed by using the raw-data until consensus was achieved and an integrated model was solidified.

\section{Results}

Two aims guided the data analysis. First, through the interview guide, team chemistry as a holistic concept was investigated. Second, within team chemistry, the components of shared 
cognition were identified. The importance of team chemistry for effective team functioning was evident across all the experts (with experts $3,6, \& 9$ being elite players and all the others elite coaches). For example, Expert 7 stated 'It [team chemistry] is very important. If you don't have chemistry and understanding between the players...you cannot form a good, strong team that can achieve accomplishments." Four themes emerged pertaining to team chemistry. The first theme centers on the interaction between the players and the coach and its effect on team chemistry. The second theme pertains to how team chemistry is affected by the interaction among the players. The third theme focuses on the effect of the team's environment on team chemistry. The last theme revolves around how members' characteristics effect the aforementioned interactions. The main categories as well as Sub-Categories (SC) and Sub-Sub-Categories (SSC) are presented in Figure 1. Figure 1 was divided into four parts correspondingly to the four themes abovementioned. Further elaboration is provided next along with supporting quotations from the data. Quotations were selected for their representativeness and relevance to the categories/subcategories. Because of the extensiveness of the model, this paper is presented as breadth over depth within any single theme and category.

\section{Interaction between the players and the coach}

Two categories revealed the importance of the interaction between the players and the coach in building team chemistry, specifically professional interaction (77 MUs) and emotional 
intelligence of coaches (15 MUs).

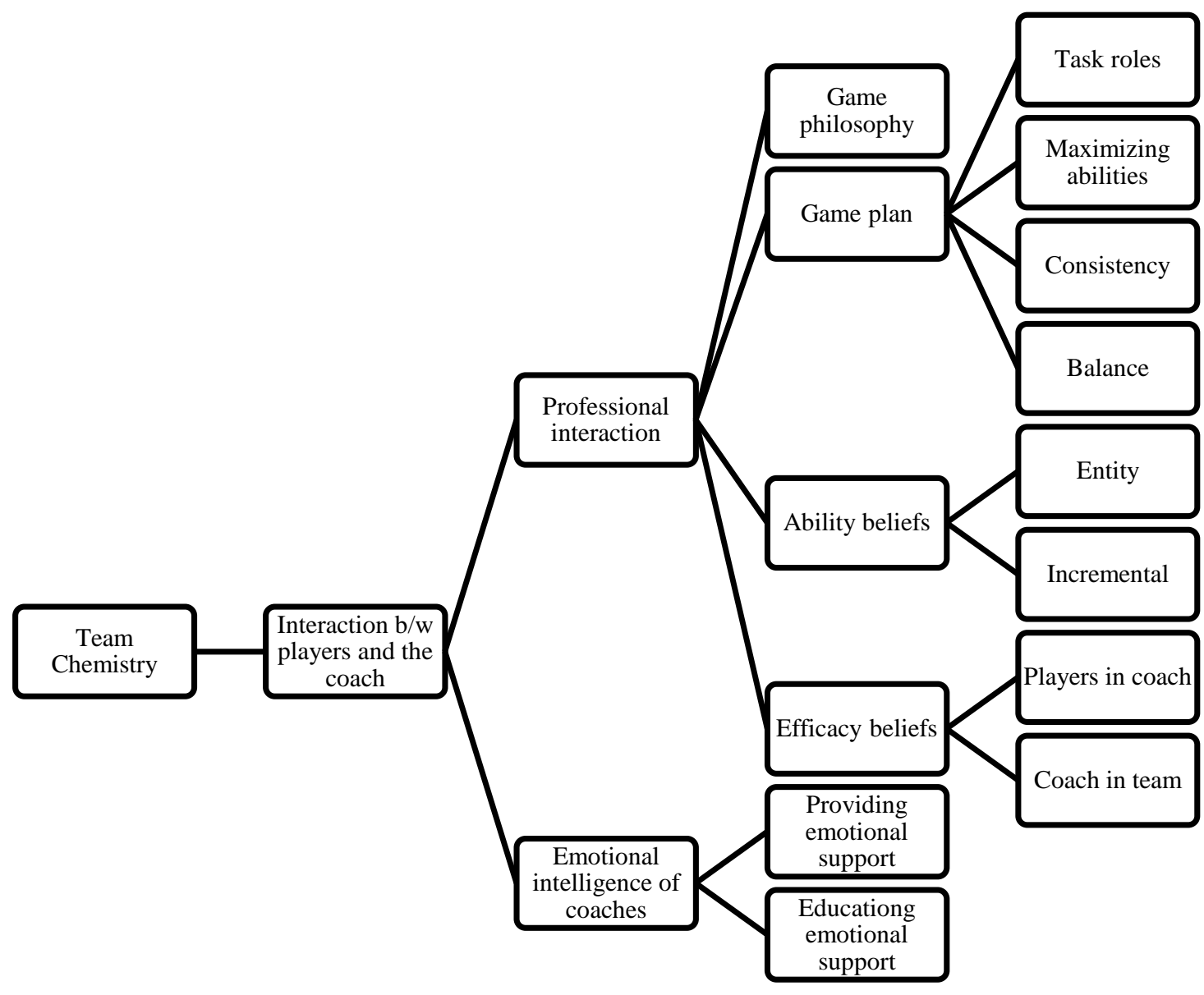

Figure 1, part 1. Team Chemistry Components: Interaction b/w players and the coach

Professional interaction. Professional interaction refers to the importance of coherent sport related cognitions and beliefs and includes four SCs: game philosophy, game plan, ability beliefs, and efficacy belief. Game philosophy refers to a more general perspective of the team's game style and centers on the agreement between the coaches and the players on elements such as offensive versus defensive attitudes, and preferred formation. For instance, Expert 9 claimed, 
"the coach should instill his game philosophy to the players, and if he sees that it is not working out then he should recruit players that match his game philosophy or adjust his own to the players' one."

Game plan (i.e., a specific plan for a certain game) was the second SC of professional interaction and includes task roles, maximizing abilities, and consistency as SSCs. An example from the data for the SC is presented below followed by three examples for the corresponding SSC: "it is super important that everyone is clear about why we are going to play according to one plan or another. Everyone should accept the game plan for it to work in the best way possible" (Expert 2), "the minute I have seen that...I thought that the players were not placed properly... as a player it affected my game...it effected the motivation on the field" (Expert 1), “it [game plan] is clearly important for team chemistry through its capacity to allow each player to channel his abilities" (Expert 2), "You have a general plan. Our team work according to a certain plan, and it is not good to change. When you frequently change and turn the plan, the chemistry vanishes as well" (Expert 1).

The third SC was termed ability beliefs, and entity (i.e., believing an ability stems mainly from innate/genetic sources) and incremental (i.e., believing an ability is mostly developmental) emerged as SSC. The experts claimed that some of the elements required for team chemistry are related to entity abilities and/or incremental abilities. Expert 3 claimed, "I believe that game intelligence is something innate. I mean, every player has a base line from which he moves on in practice. One starts from 6 and moves up to 8, another starts from 8 and gets up to 10." Expert 8 stated, "To some it comes spontaneously. Others you have to teach and it can be taught." Efficacy belief emerged as the fourth SC of professional interaction with players' efficacy in their coach and coach's efficacy in the team as SSC. Referring to efficacy in the coach, one of 
the experts elaborated on trusting the coach, "I think that trust is a very important thing...trust is knowing that everything is being done for the benefit of the team and not from some personal interests" (Expert 7). Expert 4 said, "you need to have chemistry with your coach; you have to believe in him." With regard to efficacy in the team, Expert 8 noted, "as a coach, when you don't belief in your players, the players see it. You come unprepared to practice and they sense it in seconds, its hurts the chemistry".

Emotional intelligence of coaches. Emotional intelligence of coaches comprised of the SC providing emotional support and educating players on emotional support. One of the experts exemplified how he differs in his emotional approach to his athletes based on their uniqueness:

I know that with this guy, in order to get the best out of him, I need to upset him and I used it as a coach, and I know that with another guy I can't talk because if I talk to him when he is nervous or upset it would be worse. (Expert 7).

With respect to educating his athletes, the same expert added "in many cases, I tell my players... in order to reach the goal, be a team, and develop chemistry; you have to be familiar with the weaknesses of one another, and its include the mental and emotional sides." 


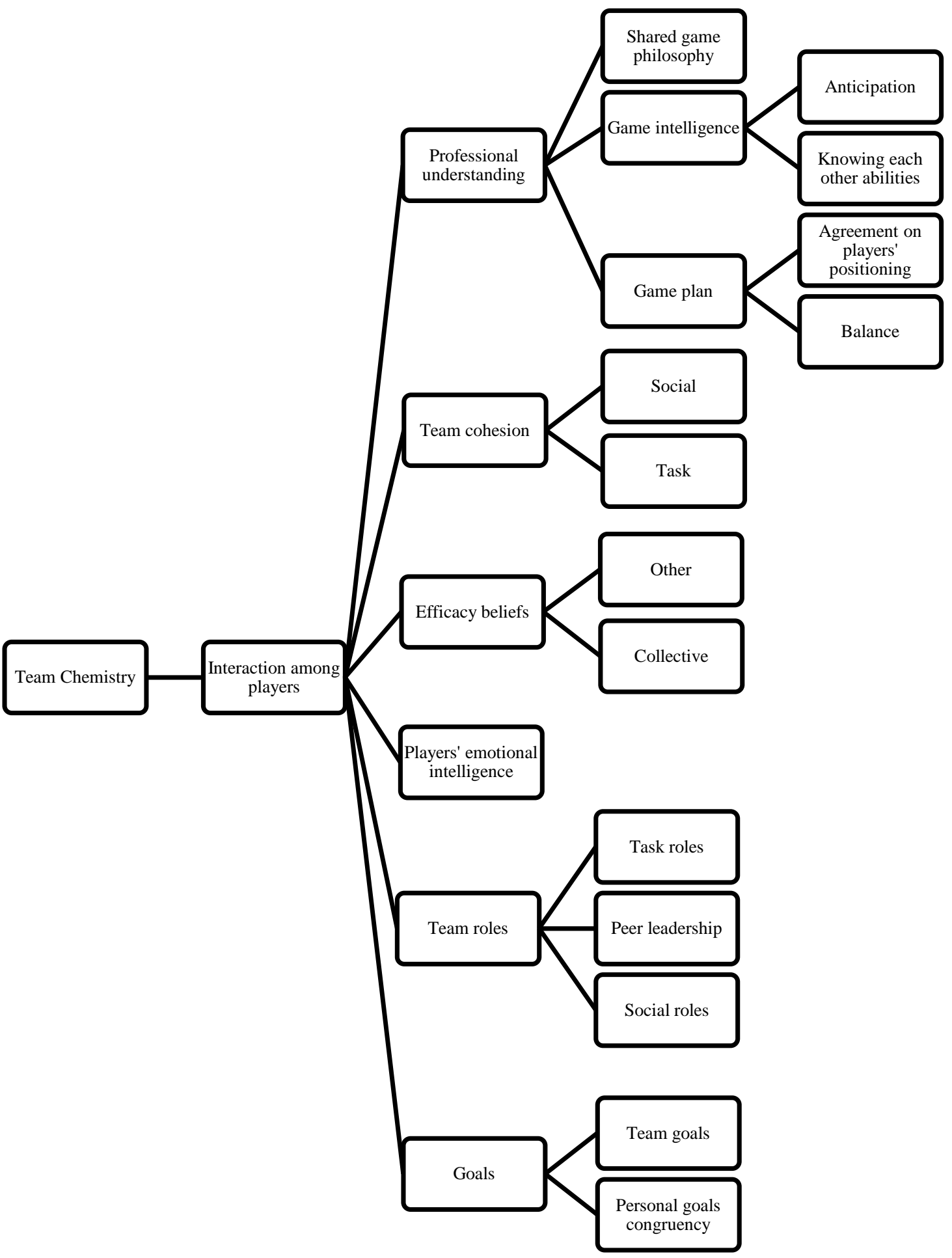

Figure 1, Part 2. Team Chemistry Components: Interaction among players 


\section{Interaction among Players}

The second theme to emerge related to the interaction among the team players. This theme corresponds to human interaction among peers at the work place in a team sport context. Professional understanding (115 MUs), team cohesion (37 MUs), efficacy beliefs (23 MUs), players' emotional intelligence (21 MUs), team roles (29 MUs), and goals (53 MUs) were the six categories to underlie this category. Examples from the data are provided for each category, $\mathrm{SC}$, and SSC.

Professional understanding. Three SCs emerged for professional understanding: shared game philosophy, game intelligence with anticipation and knowing each other abilities as SSC, and game plan (agreement on players positioning and balance as SSC). Worth noting, two elements were claimed to affect (but not underlie) the professional understanding between the players: time together and the performance outcomes. It was claimed that through long mutual exposure, players establish shared understanding. For example, Expert 6 explained, "these kind of things [shared understanding] are acquired with time...it is hard to achieve blind understanding with a new player that arrived just two weeks ago in comparison to a player that is on the team for years." The impact of the outcome (i.e., wining, tying, or losing) on professional interaction and teammates' unity around it was exemplified by Expert 5:

[Achieving team chemistry] yes, because in both teams the outcome was good right from the start. But if some players say: what is this plan, this plan doesn't fit us and bad results occur, then, their initial line of thinking is reinforced, and it is harder to bring them back, to connect them.

Pertaining to shared game philosophy, Expert 2 claimed that the players should agree $100 \%$ on the team's game philosophy. However, most of the experts agreed that players share 
game philosophy through accepting their coach's one. Expert 8 has noted on that matter:

"players accept the coach's view and they believe in it. They believe that it will lead them to good places."

Anticipation was presented as a vital requirement for establishing shared understanding. Expert 2 even postulated anticipation to be the most important aspect in having team chemistry. "These [players with anticipation abilities] are the most required players in soccer. These are players that can read a play ahead. These are players with spatial vision. The more you have in your team the more wins the team will get" (Expert 4). Expert 9 proclaimed about knowing each other abilities, "when you say team chemistry, in my opinion, it is the ability to know the strengths and weaknesses of each player in the team." Expert 1 exemplified, "you know that you have a player that is bad defensively or on his left side, and you know that a fast opponent will pass over him... as a midfielder you try to position yourself to cover up for him.”

Game plan acceptance was proposed to hold great importance. For example, Expert 2 stated, "They [the players] must feel comfortable with the style, plan, and strategy of a certain game. Acceptance can be reached through agreement on players' positioning. The following was noted, "Personally, I had several differences with the coach about positioning a player that I had hard time playing with, and the coach insisted to start with him. Most of the times he started, we lost" (Expert 9). Expert 3 claimed on that matter, "players have to think that their teammates are the best in their roles, and that they can be fully trusted." In addition, a balance within the team was suggested to positively affect the game plan. As one of the experts briefly stated, "being smart [as a coach] is creating a balance" (Expert 7). He additionally disclosed, 
When I came, I thought that the team was very talented but too soft. I brought two players to the team, not [big stars] ...gray players (i.e., players who do the "dirty" work). They came and created the necessary balance. Our team became very physical.

Team cohesion. Social and task cohesion were the two SC of team cohesion. Pertaining to social cohesion, friendship outside the field was claimed to play a big part in establishing team effectiveness. An expert shared his beliefs on that matter, "I have no doubt that if players are friends outside the pitch it is highly contributing to the team effectiveness" (Expert 6). Expert 1 exemplified, "we were meeting on Fridays and went to hotels [as a team] to consolidate the players, to bring the people closer, and I think it had positive effect."With regard to task cohesion Expert 6 postulated, "You know that the other players will be there for you. Before you fall, they will catch you...you know that if, god forbid, you'll stumble or make a mistake, there will be someone there to cover up for you."

Efficacy beliefs. Other and collective efficacies were the two SC of efficacy beliefs. Specifically, our experts have noted that believing in your teammates abilities as well in the ability of the team as a whole is crucial. For example, Expert 3 reflected on his time as a player, "Every player must have confidence...in those [teammates] around him...I have to accept the fact that for me $\mathrm{G}$ is the best defender...obviously $\mathrm{G}$ was not the best, but I perceived him to be this way.” Expert 1 pertained to collective efficacy, "when we had an excellent team, we believed in ourselves. We thought we could beat any team in the country. It increased our confidence, it increased the chemistry, and it facilitated our motivation."

Player's emotional intelligence. The importance of emotional intelligence was emphasized during games, during practices and in the locker room. For example, Expert 6 reflected, "if a player was under stress, not one but three players went to help him. If you have 
several such players, it's a blessing," and expert 5 disclosed, "I have such a player in my team...he is an asset. He captures all these things and takes care of everybody during practice... he is the team psychologist." Expert 8 added:

"Positive energy stems from emotional intelligence. When you know what is going on with each player. Knowing that sometimes players are just human beings. If a player misses from five meters and everybody yell at him, they are bringing him down, and he will bring them down in return because they are bound with one another. We depend on each other."

Team roles. Task roles, peer leadership, and social roles emerged as the SC of team roles. Accepting your role is thought of as essential for reaching full team potential. The following quotes represent this proposition:

A soccer player has to have a clear mind... he needs to know two things. One, that he is capable of doing the job he supposed to do including being positioned in the best place for him on the field, and two, that those around him, trust him. If these two do not exist, it's a waste of time. Take R for example, he can never be successful on the right wing. Why? Because he doesn't want to be there. When each player wants to do his job with all his soul, with all his heart, when he comes with a clear vision that this is my role and that's it, the outcome will be good. When each player, you know, starts to undermine the other, and wants to do other people roles, it's over. You can shut down the team. (Expert 3).

The importance of positive peer leadership to team chemistry has been scattered across the interviews. Expert 1 exemplified:

We created a condition in which players knew their role in the team. Each player knew his professional role and his position in the leading hierarchy. Who are the leaders on field, who enhances the motivation, who leads the team psychologically in crisis? 
Social roles have also been described as of great importance to maintaining positive atmosphere in the team. Expert 6 noted:

You should have a guy that knows how to say something funny to break the tension. You should have a guy that cheers the other player and says something positive when things go wrong...those who know how to comfort and lift the spirit of the less experienced ones.

Goals. Team goals and personal goals congruency underlie the goals category. Team goals emerged as a central tool to put the players on "the same page." Accordingly, the following statement was provided, "any player that joins a team must know the final goal...through the final goal he will direct himself, but the team goal is first and foremost" (Expert 3). However, several experts pointed out the possible debilitative effect of unrealistic team goals. Specifically, Expert 8 proclaimed, "These [team] goals are very important to the team chemistry because if the goals are inappropriate, lack proportional to the human sources that you have, it kills the chemistry. It kills it." Expert 1 summarized, "if the goals are unrealistic it can only damage." Pertaining to personal goals, congruency emerged to be the key for understand whether personal goal are beneficial or detrimental to the team dynamics. Expert 5 claimed, "If the player thinks only about himself and puts himself above the team, there is no doubt, it will harm the chemistry," while Expert 4 stated, "you have to direct them [personal goals] to the benefit of the team. Even if you want to be the top scorer, know how to get there. Not on the expense of the team."

\section{The Team's Environment}

Four categories emerged for the team's environment. The first and second categories centered on the team owners (10 MUs), and management (5 MUs), respectively. Team fans (3 
MUs) were the third category and media (9 MUs) emerged as the fourth category. An example for each of these categories is presented next.

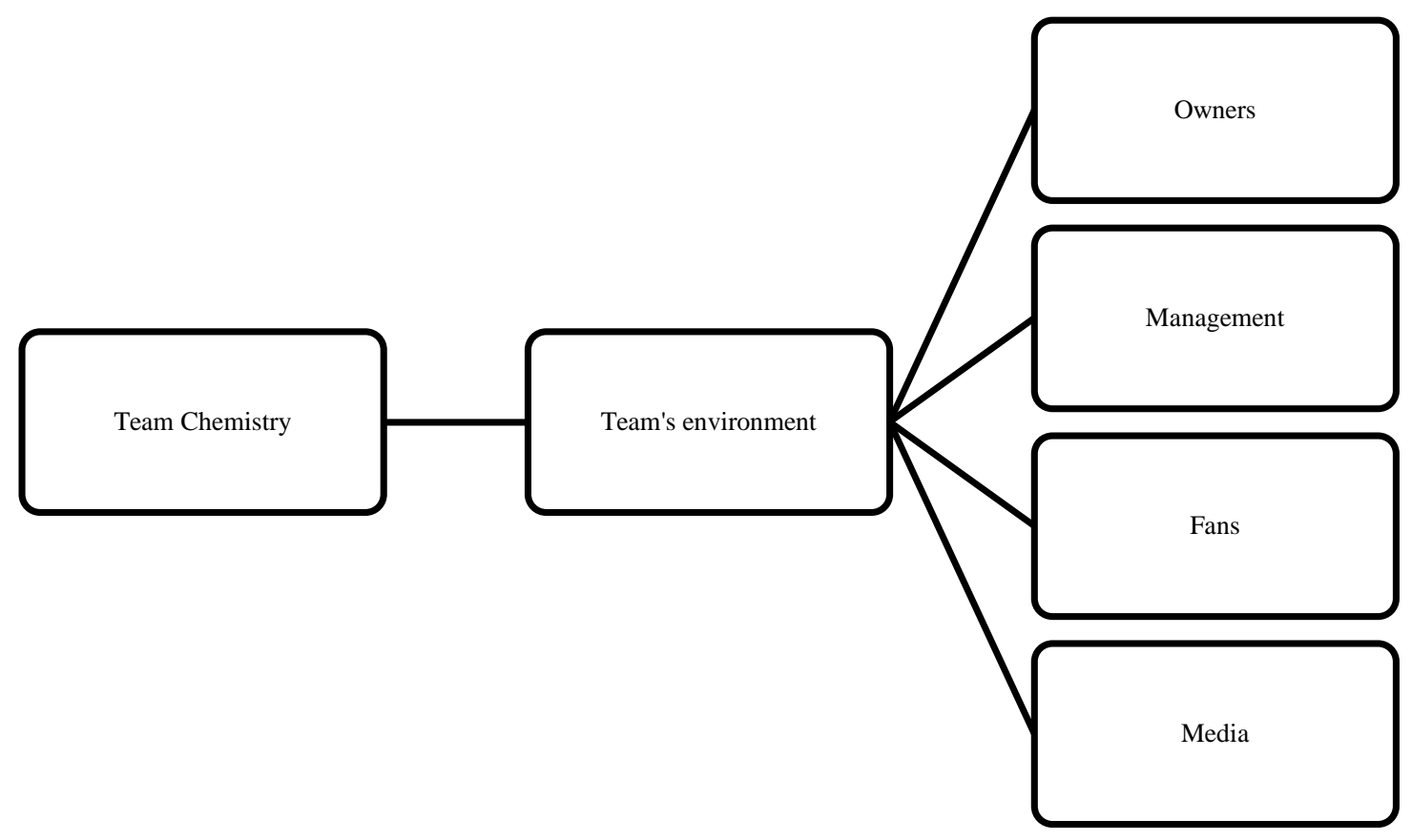

Figure 1, Part 3 Team Chemistry Components: Team's environment

Regarding the team owner the following was disclosed:

He [the team owner] came to practice out of the blue and told the player that they were not putting enough effort. He didn't sense the processes in the team, he came, threw this statement in the air and left...some players are strong enough to deal with such a statement and some get hurt. (Expert 2).

Expert 8 proclaimed, "an owner that is grumpy all the time effects the chemistry, a manager that acts as a fool and come to practice with no shirt and flip flops in the practice camp affects the chemistry." With regard to the fans, the following has been claimed, "the fans are a very important factor that can assist the chemistry to some degree when everything goes well. If not, 
they can have the opposite effect" (Expert 6). However, it was claimed that the relationship with the fans is reciprocal. Expert 8 elaborated on the effect of the media on the team:

I must deal every day with five film squads who come to interview and film the players.

The competition [over attention] is strong though sometimes not pronounced. Who will be interviewed? When? Why is a certain player interviewed and the others not? It creates tension in the team.

\section{Member's Characteristics}

The experts revealed three categories for members' characteristics: These categories are demographic data (12 MUs), on-field characteristics (27 MUs), and members' ego (38MUs). The demographic data category included two SC: experience in sport and culture. Physical abilities, technical abilities and creativity represented members on field characteristics while ego congruency and self-efficacy underlied members' ego. Examples from the data are provided.

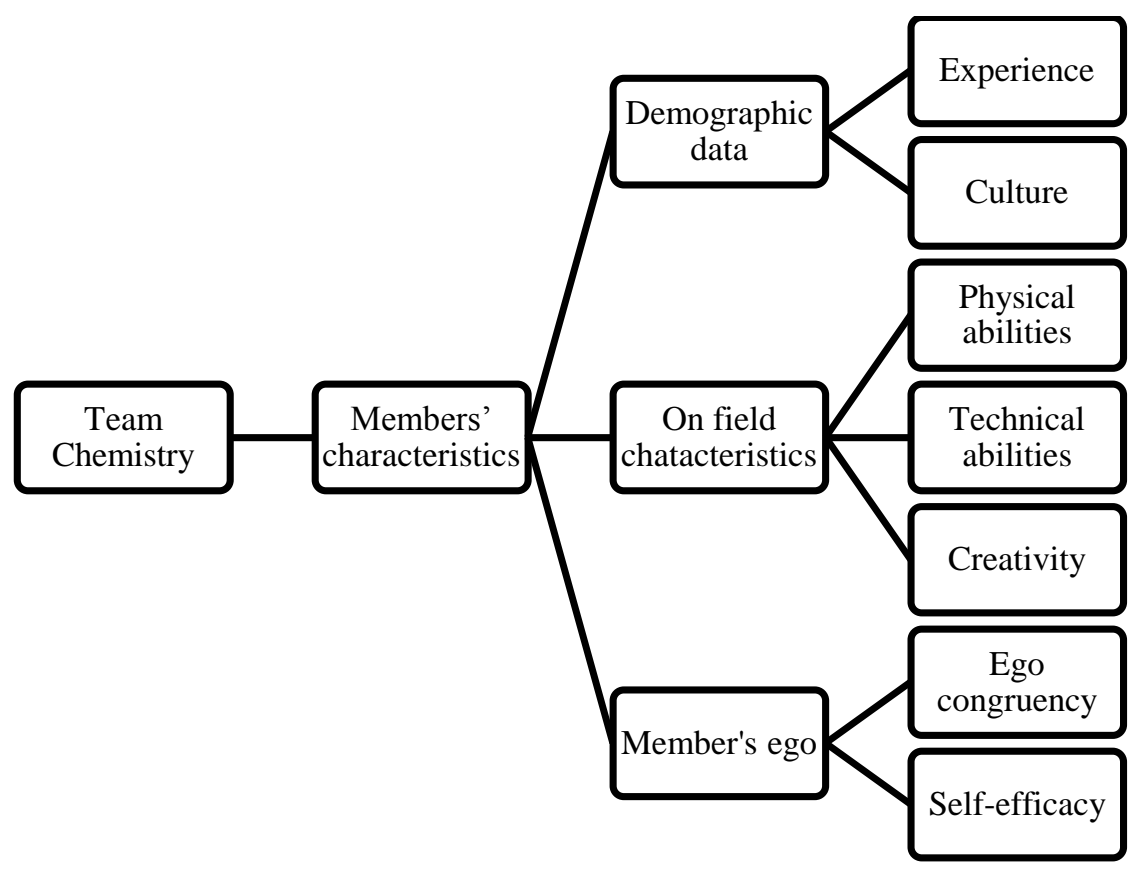

Figure 1, Part 4. Team Chemistry Components: Members' characteristics 
Demographic data. Expert 1elaborated on experience, and said, "The chemistry is built mainly from extensive experience and cooperation over a long period of time." He added, "professional players, at that level, you learn them quite fast...it is part of the experience." Pertaining to culture, Expert 5 shared his thoughts about bringing five foreign players from the same country, "five people from the same country, even though they are not in the same status, even though they are not at the same age, but they are from the same country, the same culture."

On-field characteristics. Physical abilities were noted, for example, by Expert 6 who stated that team chemistry can hardly be achieved with novices as they are limited in both their cognitive and physical abilities. Thus, even when making the right decision, performance suffers as a consequence of increasing the level of uncertainty, and reducing the probability for desired chemistry. Pertaining to technical abilities the following was postulated, "at the highest level...you have to create cooperation, but also you have to bring the most talented players" (Expert 8). Expert 6 pertained to creativity stating that "a creative player that plays in a professional league have to be one that creates something from nothing. Taking complicated situations and making them simple to handle."

Members' ego. Ego congruency emerged to direct the positive or negative impact of a player on the team. On a positive note, Expert 2 demonstrated ways to facilitate ego congruency "when a coach open the season, he tells the players to put their ego in a closet, lock it, and leave it at home... here you have to sacrifice for the team." On the negative end, expert 1 specified, "Sometimes you have ego battles between players. You have leaders, you have those who want to be leaders and think they should be...too many "stars" in one team create leadership problem, ego problems." Regarding self-efficacy, Expert 1 noted "If you believe in yourself, it brings you 
closer to victory...it's a self-fulfilling prophecy, if you don't believe in your abilities you will eventually lose the game."

\section{Discussion}

Our model of team chemistry centers on the interface among team personnel (i.e., the interaction among the players and between the players and the coach, the team's environment, and members' characteristics). This model acknowledges the collaborative effort among the team members for achieving peak performance (Colin, 2003). An important key of a successful collaboration was the interaction between the coach and the players. The crucial role of the coach is emphasized in the meditational model of leadership in sport (Smoll \& Smith, 1989).

Moreover, the coach's role is to develop and maintain a SMM among their athletes (Gershgoren et al., 2013), shape the team's motivational climate (Reinboth \& Duda, 2006), regulate stress responses and elevate self-efficacy (e.g., Passer, 1983), set goals, clarify roles, and establish inter-athlete communication (Carron, Colman, Wheeler, \& Stevens, 2002).

Peer interaction emerged as an important theme in our team chemistry model. Despite its importance to team functioning, limited effort was devoted to the leadership role of peers (Eys, Loughead, \& Hardy, 2007). At the social level, it was found that peers provide more social support than coaches (Loughead \& Hardy, 2005) and may foster strong cohesion in general (Vincer \& Loughead, 2010) and social cohesion in particular (Price \& Weiss, 2013). In terms of performance, peers are strongly involved in task-related functions such as setting strategies to attain goals (Loughead, Hardy, \& Eys, 2006), and SMM development (Filho, Gershgoren, Basevitch, Schinke, \& Tenenbaum, 2013). Furthermore, Loughead et al. found that athletes are involved in external activities, such as promoting the team within the community, and representing the team in meeting with the coach. 
The importance of the management/owners, media, and fans in team sports has also been acknowledged in the literature. Recently, Kristiansen, Halvari, and Roberts (2012) found that media coverage imposes feeling of stress on athletes through the organization leaders' demands (see also Fletcher, Hanton, \& Mellalieu, 2006). Hence, the media through interviews and headlines may positively or negatively intervene on the personal interaction within the team. As Kristiansen, Roberts, and Sisjord (2012) exemplified, a defeated, angry, and tired athlete can easily pass the blame during an interview to someone else on the team. Fans have also been associated with media related processes and pressure. With regard to the media, increased exposure was claimed by athletes to relate to an increase in public expectations to scrutinize every act, both on and off the field (Kristiansen, Halvari, \& Roberts, 2012). In part, these expectations are facilitated by fans who are interested in closely following their beloved team. Furthermore, the evaluation made by fans was perceived by elite athletes to be an additional source of pressure they have to overcome (Kristiansen, Roberts, \& Sisjord, 2012).

In addition to the interface among team personnel, the components of our model can be further discussed through the cognitive, affective, and social lenses suggested by Gershgoren et al. (2013). The components of game intelligence, game plan, shared game philosophy, goals, and efficacy beliefs along with their respective associated subcomponents are discussed under the cognitive dimension. Emotional intelligence and ego congruency are viewed within the affective dimension. Lastly, components such as team cohesion, team roles, leadership, and the team's environment are discussed through social lenses. Exploring several psychological dimensions simultaneously (i.e., cognition, emotions, and social) while investigating human performance was noted as an appropriate holistic approach (see Eccles \& Tenenbaum, 2007; Tenenbaum, et al., 2009). 


\section{Team Chemistry through Shared Cognition Lenses}

The cognitive dimension pertains to experts' perception of SMM (i.e., shared cognition). The situational cognitions of game plan and game intelligence correspond to Gershgoren et al.'s (2013) findings pertaining to tactical understanding and game intelligence. Specifically, game plan revolves around a specific strategy for a specific competition, while game intelligence represents the team members' abilities to understand each other within a specific context in the game. Therefore, the game plan provides the players with the "big picture" of a certain game. The experts emphasized that through keeping both the opposing team and their own team in mind, the game plan should: (a) take full advantage of the players' abilities and cover for their shortcoming (i.e., ability maximizing), (b) result in agreement on the players positioning (i.e., facilitate other and collective efficacy), (c) balance the players' personal and professional characteristics, and (d) be somewhat consistent over time to prevent any "shaking" of the system each game. Although the game plan provides a team level strategic baseline for performance execution, the game itself is dynamic. Thus, the players must constantly adjust their actions according to the unique course of events. The experts approached this matter using game intelligence. Underlied by anticipation skills, creativity, knowledge of one another abilities and experience in sport, game intelligence enables players to properly modify their actions as situations change.

Game philosophy and goals represent general performance cognitions. Similar to Gershgoren et al.'s (2013) study, game philosophy revolves around its consensus. Thus, reaching a shared philosophy, acceptable by all (i.e., among the players and between them and the coach) is perceived as an essential component regardless of its content. Accordingly, Reimer et al., (2006) claimed that being "on the same page" is vital for enhancing a SMM and team decision 
making. Furthermore, Reimer et al. suggested that common goals are vital in team cognition. Specifically, they noted "ideally, team members agree upon and share basic team goals. Moreover, teams hope their member goals will complement each other and be congruent with the team goals" (p. 383). This notion corresponds to the goals subcategory emerging from the experts. A specific concern pertained to the goals congruency of foreign players. The experts noted that in certain cases, foreign players perceive themselves as outsiders (e.g., as for cultural differences) to the team and the local community. In such cases, foreign players tend to focus on personal goals which are not necessarily congruent with the team goals. An additional concern pertained to the team goals themselves. The experts claimed that unrealistic team goals may impede shared cognition as team members neither buy into them nor unite around them. In such cases, more realistic goals are left unclear and open for interpretation.

Three type of efficacy beliefs emerged from the data: self-efficacy, other efficacy, and collective efficacy. In general, self-efficacy refers to one's perception of his/her capabilities to reach a certain level of attainment (Bandura, 1997). Other efficacy revolves around one's perception of his/her teammate's (i.e., including the coach) ability to perform the task at hand (Jackson, Beauchamp, \& Knapp, 2007). Collective efficacy relates to one's perception of his/her team capabilities as a collective in executing a task appropriately (Myers \& Feltz, 2007). Efficacy beliefs emerged as a cognitive construct with strong affective connections. Focusing on cognition, shared efficacy beliefs were related to knowing each other's abilities. The experts claimed that elite athletes are capable of accurately estimating their own and their teammates' abilities, and therefore, are able to create realistic efficacy beliefs. Accurate efficacy beliefs about the team and its members should assist team members to predict their teammates' actions as they understand their strengths and weaknesses. Mathieu, Rapp, Maynard, and Mangos (2010) 
found collective efficacy to mediate task SMM and team performance. Marks (1999) found that teams with high collective efficacy were more willing to adjust their strategies to a new context while teams with low collective efficacy "played it safe" and maintained their "old" strategies. This finding was supported by Expert 1 who noted that teams with low collective efficacy tend to play more defensively, and try to 'steal' the victory from the more dominating team.

Efficacy beliefs have also been related in the literature to affective states. In a recent study in golf, self-efficacy was negatively associated with state somatic and pre-round anxiety (Hayslip, Raab, Baczewski, \& Petrie, 2010). These results support Tenenbaum and Land's (2009) conceptual linkage between cognitive collapse in the decision making process, and changes in the athlete's affective state. They claimed that under pressure, anxiety increases and self-efficacy deteriorates resulting in impaired decision making. One may claim that under pressure, similar processes may occur within a team. In this vein, Expert 2 stated:

You start the game with a good feeling that we are a strong team...you feel confident and the team is playing well. Suddenly you receive a stupid goal, because your center back did a mistake, and your confidence starts to deteriorate...you pick yourself up and all of a sudden another mistake occurs. You say to yourself that something bad is happening... you start losing your faith, and now you don't believe in the player who plays next to you anymore... and before you know it, the team falls apart

\section{Team Chemistry through Affective Lenses}

Two components are discussed under the affective dimension: emotional intelligence and ego congruency. Emotional intelligence involves one's ability to identify the emotional state of others and provide support to regulate it in order to guide thoughts and actions (Salovey \& Mayer, 1990). Such support was claimed by the experts to be present mostly on field (i.e., during 
games or practices) and in the locker room (e.g., pre and post-performance, and during breaks). Rosenfeld, Richman, and Hardy (1989) found that $11 \%$ and $4 \%$ of collegiate athletes' emotional support came from teammates and coaches respectively. Indeed, emotional support offered by coaches, and especially by teammates, emerged as a matter of great importance for team functioning by our experts. Moreover, they proposed to train emotional intelligence abilities (i.e., recognizing and managing the emotions of others) in order to promote the team's optimal performance.

Ego congruency is discussed through affective lenses because our experts identified it as important to team chemistry via its positive or negative affective consequences. Specifically, the experts claimed that when athletes focus on their own benefits, and perceive themselves as above the team, negative emotions such as jealousy, bitterness, and hostility arise. Athletes who navigate the team in different directions and form team cliques evoke such emotions. These patterns are more in line with performance motivational climate in which competition and external comparison are stressed (Smith, Small, \& Curtis, 1979). In contrast, when athletes are willing to put their own ego aside and make personal sacrifices for the team, feelings of trust, respect, and harmony evolve. These processes correspond to mastery motivational climate in which cooperation is emphasized. Smith et al. (1979) found that intra-team attraction was significantly more evident in teams with higher perceived mastery motivational climate. In a classic experimental study (i.e., Deutsch, 1949), results revealed that in the intra-team competition condition, in which members became more self-centered, mistrust and conflicts were more evident resulting in poorer performance than in the cooperation condition. The aforementioned studies' results alongside the experts' views, suggest that ego congruency is not 
only connected to emotions, but also associated with team cohesion, which is a social construct in nature.

\section{Team Chemistry through Social Lenses}

Team cohesion is one of the four components being viewed under the social dimension. The other three revolve around team roles, leadership, and the team's environment. Team cohesion has become one of the most studied topics about teams as a unit of analysis (Eccles, 2010; Eccles \& Johnson 2009). Social cohesion relates to team unity around non-task related functions such as going to a movie together after practice. Task cohesion refers the ability of the team members to "stick together" while pursuing the team's instrumental objectives (Carron, Bray, \& Eys, 2002; Festinger, Schachter, \& Back, 1963; Mikalachki, 1969). For example, a task cohesive team would remain united even after a teammate made a crucial mistake resulting in the team falling behind in an important match. Task and social cohesion were highly associated with team functioning by both a meta-analysis (see Carron et al., 2002) and our experts' opinions and elaborations. Examples of our experts' statements are provided in the results section.

Team roles is the second component discussed under social lenses. Informal roles centered mainly on Social roles, whereas the formal ones focused on task roles. Social roles have been presented as essential for maintaining a team positive atmosphere on and off the field. Although this idea is very much related to team cohesion, it was discussed by the experts as a separate construct. The balance between social roles came across as of great value. One of the experts used a cuisine analogy to illustrate this notion. In his analogy, the balance between social roles was compared to a vegetable salad which should include a variety of vegetables, various spices, and dressing. Although each ingredient is important by its own, missed portions may make this 
salad uneatable. The importance of balanced roles was conceptually and empirically supported in the literature (see Belbin, 1981, 1993; Senior 1997).

Reimer et al. (2006) proclaimed that teamwork and taskwork is, among other things, established by professional roles. Through these task related roles, workload is distributed among team members. Therefore, task roles have social connotation in which dependency in others is evident. Teamwork is established as members become familiar with (a) the different task roles in their team, (b) the unique interactions among these roles, (c) the specific member who carry out the role, and (d) the context in which the role is being executed. Similar ideas were elicited by our experts. As examples were already provided at the results section, they are not repeated here.

The third component within the social dimension is leadership. Defined as "the behavioral process of influencing individuals and groups towards set goals (Barrow, 1977, p. 232), leadership appear to be a key in reaching desired level of attainment. This key was also acknowledged by the experts. There is a general agreement that in sport, the coach is the formal leader of the team. Accordingly, his/her behaviors influence the team dynamic. Recently, coaches' unfair attitudes (e.g., treating players differently according to their skill level) were claimed to arise negative affects and resentment (Gershgoren et al., 2013). However, in this investigation, peer leaders are also of high interest and thus, be next discussed.

Although our experts argued that peer leaders mostly emerge according to their athletic abilities or experience, they clarified that not every veteran player or a team star can become a leader. Peer leaders at the collegiate level were found to emerge mainly based on their experience (i.e., seniors) regardless of their skill level (Tropp \& Landers, 1979). In contrast, coaches of high school athletes based their rating of peer leadership abilities on their athletes' 
athletic abilities (Moran \& Weiss, 2006). The findings of this current study suggest that at the professional level, leadership characteristics must complement ones athletic competence and/or experience in order to become a peer leader. One of the suggested characteristics was emotional intelligence. Therefore, a peer leader is expected to provide emotional support to those athletes in need. Along those lines, one of the experts stated, "coaches today should invest more in it [emotional intelligence]. They should identify the leading players and train them to support the team and its members in crucial moments" (Expert 1).

The environment surrounding the team (i.e., external to the relationship among the players and between the players and the coach) emerged as an essential social component. This environment was comprised of the team's owners, management, fans and media. In general, the experts noted that these factors can either have positive or negative effects on the team. From the positive end, "industrial peace" can be provided, allowing the team to focus on its goals and to appropriately prepare to reach them. On a negative note, instability can be obtained, causing interpersonal problems such as internal rivalry and cliques. As these factors are mostly out of the team control, they are not further discussed in this paper.

\section{Summary}

From an applied view point, the cognitive-affective-social-behavioral linkage in team sports presented in this study may serve sport psychology consultants and coaches to better develop team chemistry intervention programs in their teams. Specifically, sport psychology practitioners are expected to accompany the recruitment procedure to assist coaches in identifying members' characteristics. Furthermore, performance enhancement consultant and coaches ought to actively participate in fostering effective team environment that enables various groups of interest (e.g., owners, coaching stuff, management, and fans) to work together towards 
shared goals. Regarding coordination, pre-process (e.g., briefing, roles allocation), in-process (SMM and communication), and post-process (e.g., video analysis of previous performances) procedures (see, Eccles \& Tenenbaum, 2004) must be facilitated to enhance the professional agreement between the coach and the players as well as among the players themselves. In addition, the emphasis on the cognitive dimension may assist professionals when designing practices and activities which aim at SMM enhancement (for a SMM facilitation model see Gershgoren et al., 2013). It is our belief that through its visual configuration, the model presented in this study may serve to develop a check-list that represents important matters that should be addressed as a team forms its shape.

Few limitations in the current study should be acknowledged. First, the author subjectivity should be pointed out, as the researcher approached this procedure with some previous knowledge pertaining to the issues under investigation (e.g., conducted previous studies on the topic). Although, as been elaborated on in the method chapter, important precautions were taken, their effectiveness cannot be clearly evaluated. Second, as the experts in this study were all Israelis, one may question their expertise level because although Israel has a well-established professional soccer league (and a fairly good national team), it is yet to be considered among the "best" leagues in the world. Nevertheless, taking into account that (a) most of the expert coaches hold the highest coaching certificate available in the world, and (b) the expert players participated substantially in international level competitions, their expertise in soccer can be seriously acknowledged. Third, the generalizability of this study's findings to other team sports is questionable to a certain degree. Indeed, a qualitative approach is not aimed at reaching generalizability but rather to capture a certain phenomenon at a certain context. Nonetheless, in 
our opinion, many of the concepts presented in this inquiry are parallel to those in other team sports and therefore, can be generalized.

Future studies may address these limitations. For example, researchers may examine quantitative techniques (e.g., neuroscience methods) to capture the cognitive-affective-socialbehavioral linkage. In addition, researchers with no previous knowledge in team dynamics may endeavor to employ a completely inductive analysis on their related data. Additional attempts may strive to glean information from subjects holding the highest level of expertise (i.e., the leading players and coaches worldwide) and from athletes/coaches (experts or non-experts) from various team sports. Future studies may also use the current findings to develop measurement tools of team chemistry and SMM in team sports in general, and soccer in particular. Last, the effectiveness of intervention programs built upon the findings and models of this inquiry may be also tested and implemented. 


\section{References}

Bandura, A. (1997). Self-efficacy: The exercise of control. New York: Freeman and Company

Barrow, J. C. (1977). The variables of leadership: A review and conceptual framework. Academy of Management Review, 2, 231-251.

Belbin, R. M. (1981). Management teams: Why they succeed or fail. London; Heinemann,

Belbin, R. M. (1993). Team roles at work. Oxford: Buccerworth-Heinemann

Braun, V., \& Clarke, V. (2006). Using thematic analysis in psychology. Qualitative Research in Psychology, 3, 77-101.

Braun, V., \& Clarke, V. (2013). Teaching thematic analysis. Methods, 26, 120-123.

Cannon-Bowers, J. A., \& Salas, E. (1998). Team performance and training in complex environments: Recent findings from applied research. Current Directions in Psychological Science, 7, 83-87.

Carron, A. V., Bray, S. R., \& Eys, M. A. (2002). Team cohesion and team success in sport. Journal of Sports Sciences, 20, 119-126.

Carron, A. V., Colman, M. M., Wheeler, J., \& Stevens, D. (2002). Cohesion and performance in sport: A meta-analysis. Journal of Sport \& Exercise Psychology, 24, 168-188.

Colin F. C. (2003). Behavioral game theory. Experiments in strategic interaction. Princeton NJ: Princeton University Press.

Creswell, J. W. (2008). Educational research: planning, conducting, and evaluating quantitative and qualitative research. New Jersey: Pearson.

Deutsch, M. (1949). A theory of co-operation and competition. Human Relations, 2, 129-152

Eccles, D. W. (2010). The coordination of labour in sports teams. International Review of Sport and Exercise Psychology, 3, 154-170. 
Eccles, D. W., \& Johnson, M. B. (2009). Letting the social and cognitive merge: New concepts for an understanding of group functioning in sport. In S. D. Mellalieu \& S. Hanton (Eds.), Applied sport psychology advances: A review (pp. 281-316). London: Routledge.

Eccles, D. W., \& Tenenbaum, G. (2004). Why an expert team is more than a team of experts: a social-cognitive conceptualization of team coordination and communication in sport. Journal of Sport \& Exercise Psychology, 26, 542-560.

Eccles, D. W., \& Tenenbaum, G. (2007). A social-cognitive perspective on team functioning in sport. In G. Tenenbaum \& R. Eklund (Eds.), Handbook of sport psychology (3rd ed.) (pp. 264-283). New York: Wiley.

Eys, M. A., Loughead, T. M., \& Hardy, J. (2007). Athlete leadership dispersion and satisfaction in interactive sport teams. Psychology of Sport and Exercise, 8, 281-296.

Festinger, L., Schachter, S., \& Back, K. (1963). Social pressures in informal groups. Stanford, CA: Stanford University Press.

Filho, E., Gershgoren, L., Basevitch, I., Schinke, R., \& Tenenbaum, G. (2014). Peer Leadership and Shared Mental Models in a College Volleyball Team: A Season Long Case Study. Journal of Clinical Sport Psychology, 8, 184-203.

Fletcher, D., Hanton, S., \& Mellalieu, S. D. (2006). An organizational stress review: Conceptual and theoretical issues in competitive sport. In S. Hanton \& S. D. Mellalieu (Eds.), Literature reviews in sport psychology (pp. 321-374). Hauppauge, NY: Nova Science.

Gershgoren, L., Filho, E. M., Tenenbaum, G., \& Schinke, R. J. (2013). Coaching shared mental models in soccer: A longitudinal case study. Journal of Clinical Sport Psychology, 7, 293312. 
Hayslip, B., Raab, C. M., Baczewski, P. C., \& Petrie, T. A. (2010). The development and validation of the golf self-efficacy scale. Journal of Sport Behavior, 33, 427-441.

Herrington, R. (2006). Team chemistry. Golf World, 26-28

Jackson, B., Beauchamp, \& M. R., Knapp, P. (2007). Relational efficacy beliefs in athlete dyads: An investigation using actor-partner interdependence models. Journal of Sport \& Exercise Psychology, 29, 170-189.

Johnson, T.E., Khalil, M. K., \& Spector, J. M. (2008). The role of acquired shared mental models in improving the process of team-based learning. Educational Technology, 48, 18-26.

Kellermanns, F. W., Floyd, S. W., Pearson, A.W., \& Spencer, B. (2008). The contingent effect of constructive confrontation on the relationship between shared mental models and decision quality. Journal of Organizational Behavior, 29, 119-137.

Klimoski, R., \& Mohammed, S. (1994). Team mental model: Construct or metaphor? Journal of Management, 20, 403-437.

Kristiansen, E., Halvari, H., \& Roberts, G. C. (2012). Organizational and media stress among professional football players: testing an achievement goal theory model. Scandinavian journal of medicine \& science in sports, 22(4), 569-579.

Kristiansen, E., Roberts, G. C., \& Sisjord, M. K. (2012). Coping with negative media content: The experiences of professional football goalkeepers. International Journal of Sport and Exercise Psychology, 9, 295-307.

Lincoln, Y. S., \& Guba, E. G. (1985). Naturalistic inquiry. Beverly Hills, CA: Sage.

Loughead, T. M., \& Hardy, J. (2005). An examination of coach and peer leader behaviors in sport. Psychology of Sport and Exercise, 6, 303-312. 
Loughead, T. M., Hardy, J., \& Eys, M. A. (2006). The nature of athlete leadership. Journal of Sport Behavior, 29, 142-158.

Lu, J., \& Lajoie, S. P. (2008). Supporting medical decision making with argumentation tools. Contemporary Educational Psychology, 33, 425-442.

Marks, M. A. (1999). A test of the impact of collective efficacy in routine and novel performance environments. Human Performance, 12, 295-309.

Mascarenhas, D. R. D., Collins, D., \& Mortimer, P. (2005). The accuracy, agreement and coherence of decision-making in rugby union officials. Journal of Sport Behavior, 28, 253271.

Mathieu, J. E., Heffner, T. S., Goodwin, G. F., Salas, E., \& Cannon-Bowers, J. A. (2000). The influence of shared mental models on team process and performance. Journal of Applied Psychology, 85, 273-283.

Mathieu, J. E., Rapp, T. L., Maynard, M. T., \& Mangos, P. M. (2010). Interactive effects of team and task shared mental models as related to air traffic controllers' collective efficacy and effectiveness. Human Performance, 23, 22-40.

Maxwell, J. A. (2001). Understanding and validity in qualitative research. In A. M. Huberman \& M. B. Miles (Eds.), The qualitative research companion (pp. 37-64). Thousand Oaks, CA: Sage.

Mclntyre, R. M., \& Salas, E. (1995). Measuring and managing for team performance: Emerging principles from complex environments. In R. Guzzo \& E. Salas (Eds.), Team effectiveness and decision making in organizations (pp. 149-203). San Francisco: Jossey-Bass.

Mikalachki, A. (1969). Group cohesion reconsidered. London, Canada: School of Business Administration, University of Western Ontario 
Mohammed, S., Ferzandi, L., \& Hamilton, K. (2010). Metaphor no more: A 15 year review of the team mental model construct. Journal of Management, 36, 876-910.

Mohammed, S., Klimoski, R., \& Rentsch, J. R. (2000). The measurement of team mental models: We have no shared schema. Organizational Research Methods, 3, 123-165.

Moran, M. M., \& Weiss, M. R. (2006). Peer leadership in sport: Links with friendship, peer acceptance, psychological characteristics, and athletic ability. Journal of Applied Sport Psychology, 18, 97-113.

Myers, N. D., \& Feltz, D. L. (2007). From self-efficacy to collective efficacy in sport:

Transitional methodological issues. In G. Tenenbaum \& R. C. Eklund (Eds.), Handbook of sport psychology (3 ${ }^{\text {rd }}$ ed., pp. 799-819). Hoboken, NJ: Wiley.

Passer, M. W. (1983). Fear of failure, fear of evaluation, perceived competence, and self-esteem in competitive-trait-anxious children. Journal of Sport Psychology, 5, 172-188.

Patton, M. Q. (2002). Qualitative research and evaluation methods (3rd ed.). Thousand Oaks, CA: Sage.

Price, M. S., \& Weiss, M. R. (2013). Relationships among coach leadership, peer leadership, and adolescent athletes' psychosocial and team outcomes: A test of transformational leadership theory. Journal of Applied Sport Psychology, 25, 265-279.

Reimer, T., Park, E. S., \& Hinsz, V. B. (2006). Shared and coordinated cognition in competitive and dynamic task environments: An information-processing perspective for team sports. International Journal of Sport and Exercise Psychology, 4, 376-400.

Reinboth, M., \& Duda, J. L. (2006). Perceived motivational climate, need satisfaction and indices of well-being in team sports: A longitudinal perspective. Psychology of Sport and Exercise, 7, 269-286. 
Rosenfeld, L. B., Richman. J. M., \& Hardy, C. J. (1989). An examination of social support networks among athletes: Description and relationship to stress. Sport Psychologist. 3, 2333.

Salas, E., Cannon-Bowers, J. A., \& Johnston, J. H. (1997). How can you turn a team of experts into an expert team?: Emerging training strategies. In C. Zsambok \& G. Klein (Eds.), Naturalistic decision making - where are we now? (pp. 359-370). Hillsdale, NJ: Erlbaum.

Salovey, P., \& Mayer, J. D. (1990). Emotional intelligence. Imagination, Cognition and Personality, 9, 185-211.

Scanlan, T. K., \& Lewthwaite, R. (1986). Social psychological aspects of competition for male youth sport participants: IV. Predictors of enjoyment. Journal of Sport Psychology, 8, 2535.

Senior, B. (1997). Team roles and team performance: Is there 'really' a link? Journal of Occupational \& Organizational Psychology, 70, 241-258.

Smith, R. E., Smoll, F. L., \& Curtis, B. (1979). Coach effectiveness training: A cognitive behavioral approach to enhancing relationship skills in youth sport coaches. Journal of Sport Psychology, 1, 59-75.

Smoll, F. L., \& Smith, R. E. (1989). Leadership behaviors in sport: A theoretical model and research paradigm. Journal of Applied Social Psychology, 19, 1522-1551.

Tenenbaum, G., \& Bar-Eli, M. (1993). Decision-making in sport: A cognitive perspective. In R. N. Singer, M. Murphey, \& L. K. Tennant (Eds.), Handbook of research on sport psychology (pp. 171-192). New York: Macmillan.

Tenenbaum, G., Hatfield, B., Eklund, R. C., Land, W, Camielo, L., Razon S., et al. (2009). Conceptual framework for studying emotions-cognitions-performance linkage under 
conditions which vary in perceived pressure. In M. Raab., J.G. Johnson., \& H. Heekeren, (Eds.), Progress in brain research: Mind and motion-the bidirectional link between thought and action (pp. 159-178). Elsevier Publication.

Tenenbaum, G., \& Land, W. M. (2009). Mental representations as an underlying mechanism for human performance. In M. Raab, J. Johnson, \& H.R. Heekeren (Eds.), Progress in brain research: Mind and motion-the bidirectional link between thought and action (pp. 251266). Elsevier Publication.

Tropp, K. J., \& Landers, D. M. (1979). Team Interaction and the emergence of leadership and interpersonal attraction in field hockey. Journal of Sport Psychology, 1, 228-240.

Vincer, D. J. E., \& Loughead, T. M. (2010). The relationship among athlete leadership behaviors and cohesion in team sports. The Sport Psychologist, 24, 448-467.

Webber, S. S., Chen, G., Payne, S. C., Marsh, S. M., \& Zaccaro, S. J. (2000). Enhancing team mental model measurement with performance appraisal practices. Organizational Research Methods, 3, 307-322.

Zhou, Y., \& Wang, E. (2010). Shared mental models as moderators of team process-performance relationships. Social Behavior and Personality, 38, 433-444. 